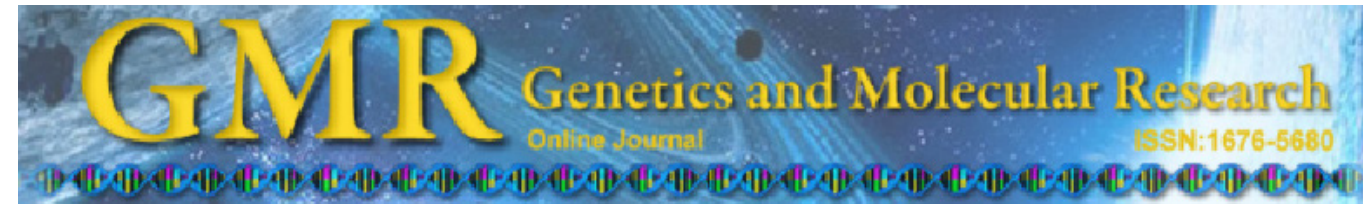

\title{
Mitotic and meiotic behavior of rye chromosomes in wheat - Psathyrostachys huashanica amphiploid $x$ triticale progeny
}

\author{
Q. Xie ${ }^{1,2 *}$, H. Kang ${ }^{1 *}$, D.L. Sparkes ${ }^{3}$, S. Tao ${ }^{1}$, X.M. Fan ${ }^{1}$, L. Xu ${ }^{1}$, X. Fan ${ }^{1}$, \\ L. Sha ${ }^{1}$, H. Zhang ${ }^{1}$, Y. Wang ${ }^{1}$, J. Zeng ${ }^{4}$ and Y. Zhou ${ }^{1,2}$ \\ ${ }^{1}$ Triticeae Research Institute, Sichuan Agricultural University, \\ Wenjiang, Chengdu, Sichuan, China \\ ${ }^{2}$ Key Laboratory of Crop Genetic Resources and Improvement, \\ Sichuan Agricultural University, Ministry of Education, Wenjiang, \\ Chengdu, Sichuan, China \\ ${ }^{3}$ Division of Plant and Crop Sciences, University of Nottingham, \\ Sutton Bonington Campus, Loughborough, Leicestershire, UK \\ ${ }^{4}$ College of Resources and Environment, Sichuan Agricultural University, \\ Wenjiang, Chengdu, Sichuan, China \\ *These authors contributed equally to this study. \\ Corresponding author: Y. Zhou \\ E-mail: zhouyh@sicau.edu.cn
}

Genet. Mol. Res. 12 (3): 2537-2548 (2013)

Received April 23, 2012

Accepted August 20, 2012

Published January 4, 2013

DOI http://dx.doi.org/10.4238/2013.January.4.16

\begin{abstract}
The dynamics of rye chromosomes during mitosis and meiosis was analyzed in a subset comprising $33 \mathrm{~F}_{3}$ lines from the cross of wheat, Psathyrostachys huashanica amphiploid (AABBDDNsNs) and hexaploid triticale (AABBRR), as visualized by genomic in situ hybridization. The results indicated that 31 of the total lines contained 4-14 rye chromosomes. Twenty-eight combinations had more rye chromosomes than the $\mathrm{F}_{1}$ hybrids, suggesting the occurrence of spontaneous quantitative increment. No $P$. huashanica chromosomes were detected in all of the combinations tested. Mitotic analysis showed that rye chromosomes progressed normally with the wheat counterparts without loss. However, abnormal meiosis was found in almost all lines.
\end{abstract}


Similar progression between wheat and rye genomes appeared from interphase to metaphase I. It was at anaphase I that many rye univalents lagged behind those of wheat, followed by equational division. This resulted in the formation of chromosomal segments and micronuclei at telophase I or II. Micronuclei could also be generated from the immobilized univalents in the periphery of cells. Synapsis and translocations between wheat and rye genomes, chromosome bridges, and unreduced gametes were detected. Therefore, it is proposed that rye chromosome elimination may involve chromatid lagging, fragmentation and micronucleation, or the immobilization of certain univalents during meiosis instead of mitosis in the relatively advanced generations. This mechanism, together with spontaneous incremental increase of rye chromosome number, permitted the generation of various germplasms for wheat improvement.

Key words: Wheat; Rye; Meiosis; Mitosis; Chromosome behavior; Genomic in situ hybridization

\section{INTRODUCTION}

Triticeae is a tribe of Poaceae, and consists of a large number of species. Some of these species are often regarded as crucial wild relatives for wheat improvement since they have numerous agronomically important traits. To introduce useful genetic variation of related species into wheat, wide crosses have been widely performed in recent decades. However, such new combinations may be subjected to strong conflicts between alien and recipient genomes and consequent reorganization (Riddle and Birchler, 2003). As a consequence, elimination of partial or complete donor chromosomes and interchange between the original parental chromosomes occur frequently during the early development of the progeny. To date, it has been documented that these events appear in both mitosis and meiosis.

During mitosis, chromosome elimination in somatic cells has been observed in many interspecific hybrids such as in crosses between Triticum aestivum L. and Zea mays L., Sorghum bicolor (L.) Moench (Inagaki and Mujeeb-Kazi, 1995), Imperata cylindrica (L.) Beauv. (Komeda et al., 2007), Hordeum vulgare L. (Barclay, 1975), Pennisetum glaucum (L.) R. Br. (Gernand et al., 2005), and between P. glaucum and T. spelta L., T. durum Desf., T. monococcum L., Secale cereale L. (Ishii et al., 2010), as well as between Hordeum species (LindeLaursen and von Bothmer, 1999; Gernand et al., 2006; Sanei et al., 2011). There is a classical model for explaining preferential chromosome elimination, which is closely associated with the formation of laggard chromosomes and micronuclei within the first few days of embryogenesis (Kasha and Kao, 1970; Davies, 1974). The micronucleated chromatin is likely to undergo heterochromatinization and DNA fragmentation, leading to loss of alien chromosomes at the end of mitosis (Gernand et al., 2005). However, the mechanism of chromosome elimination remains vague, and it may be related to the different timing of cell cycles, spatial separation of donor genomes, nuclear extrusions, malfunction of the kinetochores, etc. (Laurie and Bennett, 1989; Linde-Laursen and von Bothmer, 1999; Gernand et al., 2005; Ishii et al., 2010). Recently, an important breakthrough has been made by Sanei et al. (2011), who showed that centromere inactivity of $H$. bulbosum, caused by the loss of the centromere-specific histone 
(CENH3) owing to cell cycle asynchrony, triggers the process of uniparental chromosome elimination in unstable $H$. vulgare $\mathrm{x} H$. bulbosum hybrid plants.

In meiosis, the process of genomic reconstruction is more complicated, as the segregation of homologous chromosomes and sister chromatids need to be implemented accurately in 2 consecutive divisions. In the early combinations, lagging univalents appeared at anaphase I or II, and their behavior was likely to cause meiotic disorders (Friebe et al., 2005; Tiwari et al., 2010). Centromere orientation and the relative strength of the spindle fibers to the sister chromatid cohesion are known to be responsible for the behavior of retarded univalents (Darlington, 1939; Lukaszewski, 2010). As a result, breakage may occur across the centromere region in a lengthwise or transverse manner or across the pericentric chromatin (Darlington, 1939; Lukaszewski, 2010; Tiwari et al., 2010). For the misdivided chromosomes, several elements could be generated. These lagging chromatids and fractions then form micronuclei at first or second telophase due to the failure to enter the new nuclei, and are finally eliminated. In some instances, pericentric, telosomic, and centric (i.e., Robertsonian) translocations between different parental chromosomes have been observed as the products of the misdivision-fusion mechanism (Friebe et al., 2005) or direct synapsis and interchange. The reconstructed chromosomes are likely transmitted through generations. Detailed cases have been described in some species of Brachiaria (Risso-Pascotto et al., 2004), Fritillaria (Darlington, 1939), Paspalum (Adamowski et al., 1998), wheat (Lukaszewski, 2010), and combinations of wheat x related species in Triticeae such as Aegilops kotschyi Boss. (Tiwari et al., 2010), Elymus trachycaulus (Link) Gould ex Shinners (Friebe et al., 2005), and rye (Liusikov et al., 2005; Fradkin et al., 2009).

Rye (S. cereale L., $2 \mathrm{n}=14, \mathrm{RR})$, a small crop grown throughout the world for several centuries, is still of great importance in certain countries in northern and central Europe. This crop is a promising genetic resource for wheat improvement due to its numerous agronomical advantages, including resistance to stripe rust, powdery mildew and several pests, cold tolerance, large spikes and grains, and high spikelet fertility (Badaev et al., 1985; Carver and Rayburn, 1994; Tyrka and Chelkowski, 2004). Much study has been conducted for the introgression of its chromosomes, chromosomal segments, or alleles into wheat by wide hybridization. To date, abundant intermediates (i.e., addition, substitution, and translocation lines and triticale) have been produced. Moreover, a number of chromosomal segments of rye have been successfully adopted in the current commercial wheat cultivars such as 1RS.1BL (Carver and Rayburn, 1994).

To understand the behavior of rye chromosomes, a cross between wheat - Psathyrostachys huashanica amphiploid (PHW-SA, $2 \mathrm{n}=8 x=56$, AABBDDNsNs) and a hexaploid triticale (Zhongsi 828, 2n $=6 x=42$, AABBRR) was performed, and a subset with large variation was further selected from $\mathrm{F}_{3}$ progeny. The present study provides insights into the elimination and transmission of rye chromosomes during mitosis and meiosis as visualized by genomic in situ hybridization (GISH).

\section{MATERIAL AND METHODS}

\section{Plant materials}

A total of $239 \mathrm{~F}_{3}$ derivative lines from the cross between wheat - P. huashanica amphiploid 'PHW-SA' $(2 \mathrm{n}=8 x=56$, AABBDDNsNs) and hexaploid triticale 'Zhongsi 828 ' ( $2 \mathrm{n}$ $=6 x=42$, AABBRR) were produced (Kang et al., 2012), and a subset comprising 33 lines 
was selected at random. A wide range of variation in the morphology and agronomical traits such as plant height, tiller number (uniculm and biculm), peduncle glaucousness, spike length, leaf characters (chlorosis or curl), spike fertility, resistance to stripe rust, and earliness was observed in this population. They were expected to bear abundant variation of chromosome behavior during cell cycles. Initially, the chromosomes of $P$. huashanica were detected using GISH and all of them found to be absent (data not shown). For the characterization of rye chromosomes, a rye cultivar 'Qinling' ( $S$. cereale L., $2 \mathrm{n}=14, \mathrm{RR})$ was used as the probe and the 'Chinese Spring' common wheat (T. aestivum L., "CS", $2 n=42$, AABBDD) was used as the blocker. All of the stocks were grown under normal field conditions.

\section{Mitotic analysis}

The seeds were germinated on moistened filter papers at $25^{\circ} \mathrm{C}$, and their actively growing root tips were collected, then fixed in ethanol:acetic acid $(3: 1, \mathrm{v} / \mathrm{v})$ for $24 \mathrm{~h}$ without pretreatment. The meristem cells at each stage of mitosis were squashed in a drop of modified carbol fuchsin after hydrolyzation in $0.2 \mathrm{~N} \mathrm{HCl}$ for $3 \mathrm{~h}$. The chromosome number of 50 cells was recorded using an Olympus BX-51 microscope (Olympus, Tokyo, Japan).

\section{Meiotic analysis}

The young growing spikes were removed and fixed immediately in ethanol:chloroform:acetic acid $(6: 3: 1, \mathrm{v} / \mathrm{v})$ for $1-2$ days. One of 3 anthers in a floret during meiosis was squashed in a drop of modified carbol fuchsin. The slides were observed with an Olympus BX51 microscope, and the images at different phases of meiosis were captured using a chargecoupled device camera operated with the Olympus Micro DP70 software (Olympus). For each line, approximately 50 pollen mother cells (PMCs) from 3 individual plants were analyzed.

\section{GISH}

The rye chromosomes at each stage of mitosis and meiosis were identified by GISH. The DNA of plant materials was extracted by the hexadecyltrimethylammonium bromide method (Doyle and Doyle, 1990). The rye DNA was labeled with digoxigenin-11-dUTP probe by nick translation by following the manufacturer protocol (Roche, Mannheim, Germany), while the DNA of CS was autoclaved at $115^{\circ} \mathrm{C}$ for $10 \mathrm{~min}$ as the blocker (200-500 bp). Root tips from the same seeds used in the mitotic analysis and the remaining 2 anthers in the same florets used in the meiotic analysis were squashed in a drop of $45 \%$ acetic acid after hydrolyzation. The coverslips were removed after being frozen in liquid nitrogen. The slides were air-dried and postfixed in $4 \%$ paraformaldehyde for $10 \mathrm{~min}$ before being denatured in $70 \%$ deionized formamide for $2 \mathrm{~min}$ at $80^{\circ} \mathrm{C}$, followed by dehydration in an ethanol series $(70,95$, and $100 \%$ ) at $-20^{\circ} \mathrm{C}$. For each slide, the hybridization mixture contained $50 \%$ deionized formamide, $2 \mathrm{X}$ sodium chloride-sodium citrate buffer, $10 \%$ dextran sulfate, $0.17 \mathrm{mg} / \mathrm{mL}$ sheared herring sperm DNA (200-500 bp), 50 ng probe DNA, and 3000 ng blocking DNA. This solution was denatured at $80^{\circ} \mathrm{C}$ for $10 \mathrm{~min}$, and quickly cooled on crushed ice for $10 \mathrm{~min}$. After hybridization on a humid Petri dish at $37^{\circ} \mathrm{C}$ overnight, washes were successively performed with $2 \mathrm{X}$ sodium chloride-sodium citrate buffer $\left(42^{\circ} \mathrm{C}\right.$ for $5 \mathrm{~min}, 25^{\circ} \mathrm{C}$ for $5 \mathrm{~min}, 42^{\circ} \mathrm{C}$ for $10 \mathrm{~min}$, 
and $25^{\circ} \mathrm{C}$ for $\left.5 \mathrm{~min}\right)$ and $1 \mathrm{X}$ phosphate-buffered saline $\left(25^{\circ} \mathrm{C}\right.$ for $\left.5 \mathrm{~min}\right)$. The anti-digoxigeninfluorescein (Roche) in $1 \%$ bovine serum albumin $(2.5 \mu \mathrm{g} / \mathrm{mL})$ was used for the detection of digoxigenin. Post-immunity washes were then performed with $1 \mathrm{X}$ phosphate-buffered saline $\left(25^{\circ} \mathrm{C}\right.$ for $\left.10 \mathrm{~min}\right)$. Propidium iodide $(1.5 \mu \mathrm{g} / \mathrm{mL}$; Vector, USA) was employed to counterstain chromosomes. The slides were observed with an Olympus BX-51 fluorescence microscope and images were captured using a charge-coupled device camera (Olympus).

\section{RESULTS}

\section{Chromosome behavior of rye during mitosis}

Chromosome count at mitotic metaphase in the $\mathrm{F}_{3}$ generation of the cross between PHW-SA and Zhongsi 828 revealed that the chromosome number was variable, from 34 to 48 . Of 33 lines, 12 had 42 chromosomes. To understand the chromosome behavior of rye in wheat background during mitosis, GISH was adopted to characterize rye chromosomes at each phase (Figure 1). The results showed that there was no visual difference of mitotic progress between rye and wheat. During interphase, the rye chromatin was arranged in a largely spotted fashion, occupying specific parts of the nuclear space. These spots were generally oval, fusiform, or radial throughout a nucleus (Figure 1a). Subsequently, the rye chromosomes, together with their wheat counterparts, were spirally coiled and individual chromosomes became distinct. Two chromatids of a chromosome were linked with the centromeres. Most of the centromeres were located in the internal space or longitudinally upward while the ends of chromatids located in the external region or longitudinally downward (Figure $1 \mathrm{~b}$ and c). At metaphase, all of the chromosomes shrunk and became clearly visible, which allowed the analysis of chromosome constitutions. In the subset comprising 33 lines, 31 contained rye chromosomes, the number of which ranged from 4 to 14 (Figure 1d and e). Twenty-eight combinations had more than the haploid rye chromosome number and 10 had 14 rye chromosomes. One smaller sized chromosome appeared consistently in 2 lines (Figure 1f). In addition, translocations between rye and wheat chromosomes were identified in 2 lines (1 translocated chromosome in line 737 and 2 in line 725; Figure 1g). As the anaphase stage ensued, 2 chromatids of each rye chromosome separated and moved normally to the opposite poles, which was identical to that of wheat (Figure 1h). At telophase, the rye chromosomes began to contract in the polar regions (Figure 1i) and eventually redistributed in the 2 daughter cells in a largely spotted fashion after cytokinesis.

\section{Meiotic analysis}

The process of meiosis in the investigated lines was studied in detail. We found that only 3 lines (lines 569,749 , and 779; 12\%), carrying $2 \mathrm{n}=42$ with 14 rye chromosomes, had normal meiosis, while the remainder of the subset was abnormal (Figure 2). Specifically, all of the chromosomes appeared as long and slender threads in PMCs from leptonema to zygonema (Figure 2a), and then began to shorten and thicken. Some unpaired chromosomes were visualized in pachynema, and then became more distinct in diplonema and diakinesis when each homologous chromosome began to repel mutually. In lines 569, 749, and 779, 21 pairs of chromosomes were present in almost all of the cells (Figure 2b). At metaphase I, these bivalents were arranged at the equatorial plate in rod or ring forms (Figure $2 \mathrm{c}$ ). The remaining 30 lines, in contrast, had a number of univalents (1-12) at the equatorial plate (Figure 2d) or 
in the poles of the spindle (Figure 2e). In addition, trivalents and tetravalents were observed at a low frequency. Across all cells, the average chromosome configuration was 5.05 univalents, 14.77 ring bivalents, 3.69 rod bivalents, 0.05 trivalents, and 0.01 tetravalents per PMC. As soon as the cells reached the anaphase I, homologous chromosomes separated toward the respective poles. Those in lines 569, 749, and 779 moved regularly, and ultimately reached the polar regions almost simultaneously (Figure 2f). The majority of the others, however, showed many laggard univalents at the metaphase plate. Two sister chromatids of each chromosome divided equationally and were pulled oppositely (Figure $2 \mathrm{~g}$ ). Some of them eventually failed to enter the polar regions in which the other chromosomes started to become compact, and then formed micronuclei at telophase I (Figure 2h). Chromosome bridges were found at anaphase I or telophase I (Figure 2i). In the second division of meiosis, abnormal division was observed in numerous cells as well. Univalents from the first division remained out of the equatorial plate at metaphase II, and tended to form micronuclei at telophase II (Figure $2 \mathrm{j}$ and k). Lagging chromosomes and bridges appeared at anaphase II. Additionally, certain daughter cells from the first division (12\% of the PMCs observed) had noticeable difference in the rhythm: one might have reached metaphase II while the other was still in prophase II (Figure $2 \mathrm{j}$ ). As a result, a single PMC finally yielded only 3 microspores (triads), one of which contained a markedly bigger nucleus (i.e., unreduced gamete) than the other normal ones (Figure $2 \mathrm{k}$ ). At the end of telophase II, $71 \%$ of the examined cells generated a number of micronuclei, although the lines 569, 749, and 779 rarely did (Figure $2 \mathrm{k}$ and 1).
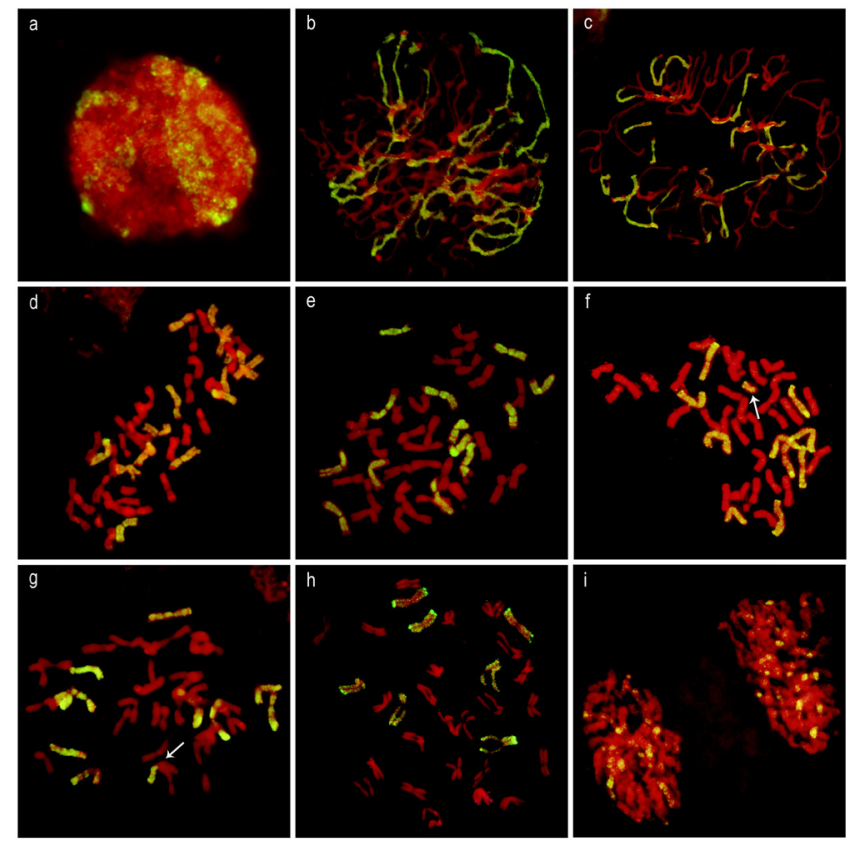

Figure 1. Chromosome behavior of rye during mitosis. For genomic in situ hybridization, the DNA of rye (RR) was used as the probe while the DNA of Chinese Spring common wheat (AABBDD) was used as the blocker. Rye chromosomes were denoted by the yellow-green fluorescence. a. Interphase. b. Middle prophase. c. Late prophase. d. Metaphase, $2 \mathrm{n}$ $=42$, showing 14 rye chromosomes. e. Metaphase, $2 n=41$, showing 13 rye chromosomes. f. Metaphase with a smaller size chromosome (arrow). g. Metaphase showing 1 translocated chromosome (arrow). h. Early anaphase. i. Telophase. 


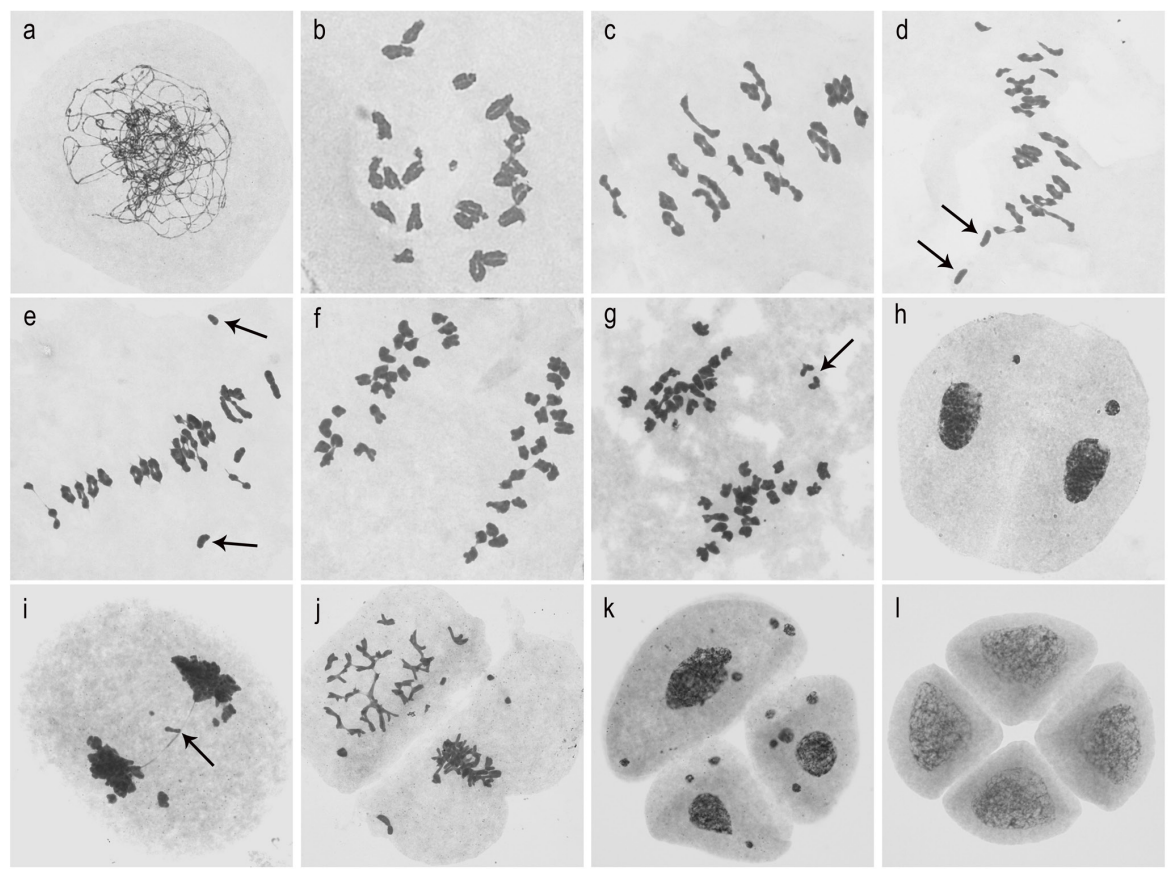

Figure 2. Meiosis in the lines investigated. a. Zygonema. b. Diplonema. c. Metaphase I, $2 \mathrm{n}=42=15 \mathrm{II}($ ring) + 6 II (rod). d. Metaphase I showing 2 univalent (arrows) at the metaphase plate, $2 \mathrm{n}=42=2 \mathrm{I}+17 \mathrm{II}$ (ring) $+3 \mathrm{II}$ (rod). e. Metaphase I showing 2 univalent (arrows) in the periphery of equatorial plate, $2 n=45=3$ I +14 II (ring) + 7 II (rod). f. Anaphase I showing normal segregation. g. Anaphase I showing a lagging univalent with equational division (arrow). h. Telophase I showing 2 micronuclei. i. Telophase I showing a chromosome bridge (arrow). j. Different progress of the second division in a pollen mother cell (1 daughter cell at prophase II and the other at metaphase II). k. A triad containing 1 unreduced gamete and 2 normal gametes accompanied with micronuclei. $\mathbf{l}$. A normal quartet.

\section{Chromosome behavior of rye during meiosis}

Rye chromosome number and pairing patterns in the PMCs of the $\mathrm{F}_{1}$ hybrids were identified first. We confirmed that only 7 univalents existed consistently in these plants (Figure 3a). Then, GISH was employed to observe rye chromosome behavior across each stage of meiosis in the $\mathrm{F}_{3}$ generation (Figure $3 \mathrm{~b}-1$ ). The results indicated that the progress of the wheat and rye chromosomes was identical until metaphase I, and subsequently differentiated at anaphase I. Specifically, the rye chromatin appeared as slender threads similar to those of wheat from leptonema to zygonema. At pachynema, the chromosomes of both species shortened and thickened simultaneously. Some of rye chromosomes remained unpaired, while the remaining chromosomes formed bivalents (Figure 3b). Their chiasmas could be easily observed at the terminal positions of the chromosomes from diplonema to diakinesis. As the cells reached the metaphase I, 14 rye chromosomes formed 7 bivalents in lines 569, 749, and 779 (Figure $3 \mathrm{c})$; the others had 0-6 bivalents of rye clustering at the equatorial plate. The univalents from rye were distributed either at the equatorial plate (Figure 3d) or in the periphery (Figure 3e). Meanwhile, bivalents with translocated chromosomal segments from rye were observed in 2 
lines ( 1 translocated bivalent in line 737 and 2 in line 725; Figure 3f), and multivalents containing 1 or 2 rye chromosomes were observed in $8 \%$ of the cells examined as well (Figure $3 \mathrm{~g}$ ). The homologous chromosomes in lines 569, 749, and 779 showing normal pairing at metaphase I were able to migrate normally to the poles at anaphase I (Figure $3 \mathrm{~h}$ ). However, the remaining combinations failed to progress in this fashion. Numerous laggard chromosomes from rye were observed at early anaphase I, and these chromosomes then underwent an equational division (Figure 3i). Portions of these chromosomes were unable to reach the poles and were eventually merged into the other chromosome groups (Figure 3j). During this period, a few chromosomal fractions of rye were produced (Figure $3 \mathrm{i}$ and $\mathrm{j}$ ). In addition, chromosome bridges were also found in many cells (Figure 3k). At telophase I, the majority of PMCs possessed a number of micronuclei from rye that were excluded from the polar groups of chromosomes (Figure 31). In the second division, similar behavior was noted. Lag and bridges of rye chromosomes were observed in the 2 daughter cells at anaphase II. Finally, a quartet or triad was produced; they usually carried a number of micronuclei that resulted from the lagging chromatids or univalents that remained immobilized in the cell periphery.
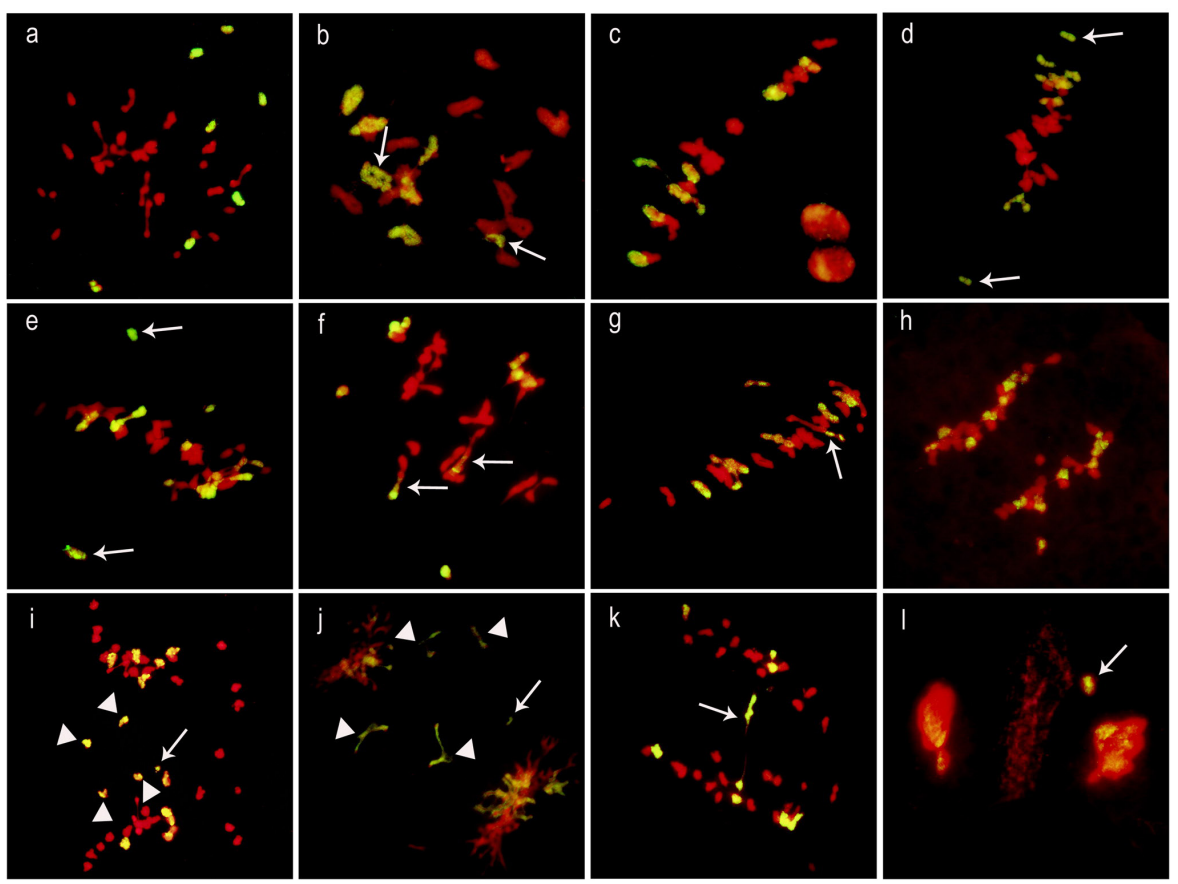

Figure 3. Chromosome behavior of rye during meiosis. For genomic in situ hybridization, the probe and blocker were described earlier. a. Metaphase $\mathrm{I}$ in $\mathrm{F}_{1}$ hybrids, showing 7 univalents from rye. b. Diplonema in $\mathrm{F}_{3}$ plants, showing 6 bivalents and 2 univalents (arrows) from rye. c. Metaphase $\mathrm{I}$ in $\mathrm{F}_{3}$ plants, showing 7 rye bivalents. d. Metaphase $\mathrm{I}$ in $\mathrm{F}_{3}$ plants, showing 2 univalents of rye staying at the equatorial plate (arrows). e. Metaphase $\mathrm{I}$ in $\mathrm{F}_{3}$ plants, showing 2 univalents of rye arranged in the periphery (arrows). f. Metaphase I in $\mathrm{F}_{3}$ plants, showing 2 translocated chromosomes (arrows). g. Metaphase $\mathrm{I}$ in $\mathrm{F}_{3}$ plants, showing 1 trivalent containing 1 rye chromosome (arrow). $\mathbf{h}$. Anaphase $\mathrm{I}$ in $\mathrm{F}_{3}$ plants, showing normal segregation. i. Middle anaphase $\mathrm{I}$ in $\mathrm{F}_{3}$ plants, showing 4 rye chromatids after equational division (arrowheads) and a chromosomal fraction (arrow). j. Late anaphase $\mathrm{I}$ in $\mathrm{F}_{3}$ plants, showing 4 rye chromatids after equational division (arrowheads) and a chromosomal fraction (arrow). k. Anaphase I in $\mathrm{F}_{3}$ plants, showing a chromosome bridge (arrow). l. Telophase I in $\mathrm{F}_{3}$ plants, showing a micronucleus of rye (arrow). 


\section{DISCUSSION}

An attempt to clarify the process of rye chromosome elimination during mitosis and meiosis was made in this study. During mitosis, rye chromatids could be yielded and segregated regularly; consequently, 2 identical daughter cells were produced, indicating that there was no loss of rye chromosomes during the process. In contrast, previous research in several interspecfic hybrid embryos showed that partial or complete uniparental chromosome elimination occurred within a short time after fertilization (Feldman et al., 1997; Gernand et al., 2005; Ishii et al., 2010; Sanei et al., 2011). Thus, it may be speculated that the elimination of rye chromosomes takes place in the early stage of embryo development, as intergenomic conflicts are rather strong, but not in relatively advanced generations. As for meiosis, however, there were numerous micronuclei, as a form of rye chromosome elimination, present at telophase I and II. This suggests that the meiotic process can continue and eliminate rye chromosomes in the population. These micronuclei resulted from two processes. In the first, the rye univalents clustering at the equatorial plate at meiotic metaphase I underwent an equational segregation at anaphase I. Parts of the chromatids lagged and failed to enter the newly produced nuclei, and in turn generated micronuclei at telophase I and II. These events have been observed in other wheat-rye combinations (Liusikov et al., 2005; Silkova et al., 2008; Fradkin et al., 2009). In the second, the immobilized univalents in the periphery of cells across meiosis could give rise to the production of micronuclei. This immobilization may be related to the malfunction of sister kinetochores, leading to a failure of spindle microtubule attachment (Sanei et al., 2011).

On the other hand, an increment of rye chromosome number was observed in the 28 lines studied. These lines had more rye chromosomes than the $\mathrm{F}_{1}$ hybrids, in which the number was $\mathrm{N}=7$. Interestingly, 10 lines included 14 chromosomes from rye. It appears that the number of rye chromosomes increased spontaneously before the $\mathrm{F}_{3}$ generation. A similar tendency has been reported in several previous studies (Bernardo et al., 1988; Fradkin et al., 2009). In the present study, this result may be attributed to 2 consecutive meiotic events: the equational division of rye univalents occurring at anaphase I and the production of unreduced gametes. Equational segregation of univalents from rye in anaphase $I$ in the early generations (e.g., $F_{1}$ ) permits the formation of 2 daughter cells carrying the same rye chromosome number as the somatic cells. Occasionally, some daughter cells ( $12 \%$ of PMCs examined in the $\mathrm{F}_{3}$ generation) might be subjected to nondivision at anaphase II, leading to the production of unreduced gametes. Afterwards, a normal zygote could be yielded after fertilization of the unreduced egg by an unreduced sperm, and then develop into a plant carrying incremental, or even double-chromosome number. Equational division and unreduced gametes are fairly common phenomena during the gametogenesis of wheat-rye derivatives. In general, the equational segregation of univalents at anaphase I and nondisjunction at anaphase II will yield unreduced gametes (Maan and Sasakuma, 1977; Shchapova et al., 1987; Silkova et al., 2008). In addition, chromosome nondisjunction sometimes occurs in the first division followed by equational segregation in the second division; afterwards, restitution nuclei could be produced (Islam and Shepherd, 1980; Xu and Joppa, 1995; Silkova et al., 2003). The division of centromeres of the sister chromatids of univalents partly depends on the presence of certain rye chromosomes (e.g., 1R, 5R, and 6R; Silkova et al., 2008). It is well known that unreduced gametes or meiotic restitution is of predominant importance in polyploidization and speciation. This phenomenon has been reported in alfalfa (Pfeiffer and Bingham, 1983), barley (Finch and Bennet, 1979), potato (Conicella et al., 1996), and other species in Triticeae (Tiwari et al., 2008; Zhang et al., 2008). 
Rye is one of the most popular related species for wheat improvement in the past decades. This may be partly because its chromosomes in a wheat background are likely to undergo a loss or a spontaneous increment, 2 events that facilitate the production of novel germplasms. Elimination of a partial or total rye genome allows the generation of additional lines or haploids, while spontaneous increment provides a chance to create partial or complete amphiploids (tetraploid, hexaploid, or octaploid triticales). In our report, 2 lines do not carry any rye chromosomes, thus they can be used as new tetraploid wheat with absence of a partial D genome. Eighteen lines have 4-13 rye chromosomes, and they are potential intermediates for production of additional lines. Of note, 7 lines contain 14 rye chromosomes, although their meiosis is abnormal. Three lines (lines 569, 749, and 779) have regular meiotic progress, and they can be considered as putative new hexaploid triticales. These putative triticales possess consistent meiotic rhythm. In addition to the intermediate products above, synapsis and translocations between wheat and rye chromosomes occurred at a relatively high frequency. Therefore, the homology between the genomes of wheat and rye may also be utilized as a powerful tool for introgression of small chromosomal segments with desirable genes.

In summary, rye chromosomes as donors are more likely to undergo a loss during meiosis than mitosis in the present instance. Anaphase I and II may be the key stages in which the lagging chromosomes are generated. These univalents underwent equational division at anaphase I, and some of the chromatids subsequently formed chromosomal fractions and micronuclei that were eventually excluded from the reformed daughter nuclei. Micronuclei could also be produced from the immobilized univalents in the periphery of PMCs. Besides, spontaneous increment of rye chromosome number occurred at the early stages of germplasm development. Both events of rye chromosomes in wheat (loss or increment) can be used for production of novel intermediate germplasms, and underscore the value of introducing exotic variation into wheat.

\section{ACKNOWLEDGMENTS}

Research supported by the National Natural Science Foundation of China (\#31101151), the State Transgenic Project (\#2011zx08009-001), the National High-Tech R\&D Program of China (863 Program; \#2011AA100103-02), the Special Fund for Agro-Scientific Research in the Public Interest of China (\#201003021), the Natural Science Foundation for Young Scientists of Sichuan Province, China (\#2010JQ0046), and the Education Bureau and Science and Technology Bureau of the Sichuan Province, China.

\section{REFERENCES}

Adamowski EV, Pagliarini MS and Batista LAR (1998). Chromosome elimination in Paspalum subciliatum (Notata group). Sex. Plant Reprod. 11: 272-276.

Badaev NS, Badaeva ED, Bolsheva NL, Maximov NG, et al. (1985). Cytogenetic analysis of forms produced by crossing hexaploid triticale with common wheat. Theor. Appl. Genet. 70: 536-541.

Barclay IR (1975). High-frequencies of haploid production in wheat (Triticum aestivum) by chromosome elimination. Nature 256: 410-411.

Bernardo A, Luengo P and Jouve N (1988). Chromosome constitution in G2 and G3 progenies of 6x-Triticale x $T$. turgidum L. hybrids. Euphytica 37: 157-166.

Carver BF and Rayburn AL (1994). Comparison of related wheat stocks possessing 1B or 1RS.1BL chromosomes: agronomic performance. Crop Sci. 34: 1505-1510. 
Conicella C, Genualdo G, Errico A, Frusciante L, et al. (1996). Meiotic restitution mechanisms and $2 n$ pollen formation in a Solanum tuberosum dihaploid and in dihaploid x wild species hybrids. Plant Breed. 115: 157-161.

Darlington CD (1939). Misdivision and the genetics of the centromere. J. Genet. 37: 341-364.

Davies DR (1974). Chromosome elimination in inter-specific hybrids. Heredity 32: 267-270.

Doyle JJ and Doyle JL (1990). Isolation of plant DNA from fresh tissue. Focus 12: 13-15.

Feldman M, Liu B, Segal G, Abbo S, et al. (1997). Rapid elimination of low-copy DNA sequences in polyploid wheat: a possible mechanism for differentiation of homoeologous chromosomes. Genetics 147: 1381-1387.

Finch RA and Bennet MD (1979). Action of triploid inducer (tri) on meiosis in barley (Hordeum vulgare L.). Heredity 43: 87-93.

Fradkin M, Greizerstein E, Paccapelo H, Ferreira V, et al. (2009). Cytological analysis of hybrids among triticales and trigopiros. Genet. Mol. Biol. 32: 797-801.

Friebe B, Zhang P, Linc G and Gill BS (2005). Robertsonian translocations in wheat arise by centric misdivision of univalents at anaphase I and rejoining of broken centromeres during interkinesis of meiosis II. Cytogenet. Genome Res. 109: 293-297.

Gernand D, Rutten T, Varshney A, Rubtsova M, et al. (2005). Uniparental chromosome elimination at mitosis and interphase in wheat and pearl millet crosses involves micronucleus formation, progressive heterochromatinization, and DNA fragmentation. Plant Cell 17: 2431-2438.

Gernand D, Rutten T, Pickering R and Houben A (2006). Elimination of chromosomes in Hordeum vulgare x H. bulbosum crosses at mitosis and interphase involves micronucleus formation and progressive heterochromatinization. Cytogenet. Genome Res. 114: 169-174.

Inagaki MN and Mujeeb-Kazi A (1995). Comparison of polyhaploid production frequencies in crosses of hexaploid wheat with maize, pearl millet and sorghum. Breed. Sci. 45: 157-161.

Ishii T, Ueda T, Tanaka H and Tsujimoto H (2010). Chromosome elimination by wide hybridization between Triticeae or oat plant and pearl millet: pearl millet chromosome dynamics in hybrid embryo cells. Chromosome Res. 18: 821-831.

Islam AKMR and Shepherd KW (1980). Meiotic restitution in wheat-barley hybrids. Chromosoma 79: 363-372.

Kang HY, Zhong MY, Xie Q and Zhang HQ (2012). Production and cytogenetics of trigeneric hybrid involving Triticum, Psathyrostachys and Secale. Genet. Resour. Crop Evol. 59: 445-453.

Kasha KJ and Kao KN (1970). High frequency haploid production in barley (Hordeum vulgare L.). Nature 225: 874-876.

Komeda N, Chaudhary HK, Suzuki G and Mukai Y (2007). Cytological evidence for chromosome elimination in wheat X Imperata cylindrica hybrids. Genes Genet. Syst. 82: 241-248.

Laurie DA and Bennett MD (1989). The timing of chromosome elimination in hexaploid wheat x maize crosses. Genome 32: 953-961.

Linde-Laursen I and von Bothmer R (1999). Orderly arrangement of the chromosomes within barley genomes of chromosome-eliminating Hordeum lechleri x barley hybrids. Genome 42: 225-236.

Liusikov OM, Bel'ko NB, Shchet'ko IS and Gordeî IA (2005). Construction of rye-wheat amphidiploids with the cytoplasm of rye-secalotriticum (RRAABB, $2 n=42$ ): meiosis characteristics in rye-triticale $\mathrm{F}_{1}$ hybrids (RRABR, $5 x$ =35). Genetika 41: 902-909.

Lukaszewski AJ (2010). Behavior of centromeres in univalents and centric misdivision in wheat. Cytogenet. Genome Res. 129: 97-109.

Maan SS and Sasakuma T (1977). Fertility of amphihaploids in Triticinae. J. Hered. 68: 87-94.

Pfeiffer TW and Bingham ET (1983). Abnormal meiosis in alfalfa, Medicago sativa: cytology of $2 N$ egg and $4 N$ pollen formation. Can. J. Genet. Cytol. 25: 107-112.

Riddle NC and Birchler JA (2003). Effects of reunited diverged regulatory hierarchies in allopolyploids and species hybrids. Trends Genet. 19: 597-600.

Risso-Pascotto C, Pagliarini MS, Borges do Valle C and Jank L (2004). Asynchronous meiotic rhythm as the cause of selective chromosome elimination in an interspecific Brachiaria hybrid. Plant Cell Rep. 22: 945-950.

Sanei M, Pickering R, Kumke K, Nasuda S, et al. (2011). Loss of centromeric histone $\mathrm{H}_{3}\left(\mathrm{CENH}_{3}\right)$ from centromeres precedes uniparental chromosome elimination in interspecific barley hybrids. Proc. Natl. Acad. Sci. U. S. A. 108: E498-E505.

Shchapova AI, Potapova TA and Kravtsova LA (1987). Genetic determination of meiotic chromosome nondisjunction in wheat-rye polyhaploids. Genetika 23: 473-481.

Silkova OG, Shchapova AI and Kravtsova LA (2003). Mechanisms of meiotic restitution and their genetic regulation in wheat-rye polyhaploids. Genetika 39: 1505-1515.

Silkova OG, Peresmyslova EE, Shchapova AI and Shumny̌ VK (2008). Genetic regulation of the centromere division in rye and wheat univalent chromosomes in dimonosomics during meiotic anaphase I. Genetika 44: 102-111.

Tiwari VK, Rawat N, Neelam K, Randhawa GS, et al. (2008). Development of Triticum turgidum subsp. durum - Aegilops 
longissima amphiploids with high iron and zinc content through unreduced gamete formation in $\mathrm{F}_{1}$ hybrids. Genome 51: 757-766.

Tiwari VK, Rawat N, Neelam K, Kumar S, et al. (2010). Random chromosome elimination in synthetic Triticum - Aegilops amphiploids leads to development of a stable partial amphiploid with high grain micro- and macronutrient content and powdery mildew resistance. Genome 53: 1053-1065.

Tyrka M and Chelkowski J (2004). Enhancing the resistance of triticale by using genes from wheat and rye. J. Appl. Genet. 45: 283-295.

Xu SJ and Joppa LR (1995). Mechanisms and inheritance of first division restitution in hybrids of wheat, rye, and Aegilops squarrosa. Genome 38: 607-615.

Zhang L, Chen Q, Yuan Z, Xiang Z, et al. (2008). Production of aneuhaploid and euhaploid sporocytes by meiotic restitution in fertile hybrids between durum wheat Langdon chromosome substitution lines and Aegilops tauschii. J. Genet. Genomics 35: 617-623. 